\title{
Research of distribution of information flows in a network
}

\author{
Politanskyi R. L. ${ }^{1}$, Zarytska O. L. ${ }^{2}$, Vistak M. V. ${ }^{3}$, Vlasenko V. V. ${ }^{1}$ \\ ${ }^{1}$ Yuriy Fedkovych Chernivtsi National University, \\ 2 Kotsyubynsky Str., 58012, Chernivtsi, Ukraine \\ ${ }^{2}$ Lviv Polytechnic National University, \\ 12 S. Bandera Str., 79013, Lviv, Ukraine \\ ${ }^{3}$ Danylo Halytsky Lviv National Medical University, \\ 69 Pekarska Str., 79010, Lviv, Ukraine
}

(Received 13 October 2021; Revised 12 November 2021; Accepted 19 November 2021)

\begin{abstract}
The algorithm for determining information flows in the network is developed and studied, taking into account restrictions on the input and output flows values in each node of the system. The algorithm is based on the Gaussian method of solving linear equations systems in case when the rank of the equivalent system matrix, is less than the number of unknown variables in the system. Using this algorithm, the capacities of sets of the integer solutions for networks with 2 nodes (flow intensity up to 200), 3 nodes (flow intensity up to 20) and 4 nodes (flow intensity up to 10) are calculated.
\end{abstract}

Keywords: Gaussian method, the set of solutions of systems of linear equations, transport network.

2010 MSC: 15A03, 15A06, 68-04, 68R99

DOI: $10.23939 / \mathrm{mmc} 2021.04 .821$

\section{Introduction}

New mobile standards need to use new frequency resources in the range of $1-30 \mathrm{GHz}$. That's why it is necessary to study the information transfer methods aimed at improving energy efficiency (i.e. reducing energy costs), including artificial intelligence [1] for frequency allocation, blockchain technology for infrastructure sharing, and the search for new signal generation methods and their modulation [2-5] to overcome intersymbol and interchannel interference. All this leads to a global trend in the development of telecommunications technologies in the direction of their convergence [6].

Quantitative analysis of network states often reduces to problems related to two-dimensional matrices, with restrictions on the flows values. Therefore, recently, a number of studies have been conducted using such sections of modern mathematics as topology and tensor analysis [7]. A number of theories and approximations have been developed that are successfully applied to networks of different origins, and combined by specifying the term "transport network". The classic task of research of transport networks is a problem where the total values of the traffic, absorbing or generating each node of this network, are set. In this formulation, this problem can be solved by classical methods of the linear algebra in order to obtain the whole set of solutions for networks of small dimension (up to five nodes). For the larger networks, the method enables to obtain all solutions of the problem close to a certain state. This state of the network can be considered as one of the most probable state with optimized values of the information flows.

\section{Problem Statement}

We assume that each node of the network is an equal participant and can be both a source and a drain of information flow. In this case, the matrix of information flows is a square $n \times n$, matrix 


$$
I_{n, n}=\left(\begin{array}{cccc}
i_{1,1} & i_{1,2} & \ldots & i_{1, n} \\
i_{2,1} & i_{2,2} & \ldots & i_{2, n} \\
\ldots & \ldots & \ldots & \ldots \\
i_{n, 1} & i_{n, 2} & \ldots & i_{n, n}
\end{array}\right)
$$

The rows of the matrix are the values of incoming traffic in each node, and the columns are the values of outgoing traffic for each node of the system. Then for the information matrix, flows of $n \times n$ the of linear equations system can be rewritten in form (2):

$$
f(n)=\left\{\begin{array}{l}
i_{1,1}+i_{1,2}+\ldots+i_{1, n-1}+i_{1, n}=\sum_{j=1}^{n} i_{1, j}=s_{1} \\
i_{2,1}+i_{2,2}+\ldots+i_{2, n-1}+i_{2, n}=\sum_{j=1}^{n} i_{2, j}=s_{2} \\
\ldots \ldots \ldots \ldots \ldots \ldots \ldots \ldots \ldots \ldots \ldots \ldots \ldots \ldots \\
i_{n-1,1}+i_{n-1,2}+\ldots+i_{n-1, n-1}+i_{n-1, n}=\sum_{j=1}^{n} i_{n-1, j}=s_{n-1} \\
i_{n, 1}+i_{n, 2}+\ldots+i_{n, n-1}+i_{n, n}=\sum_{j=1}^{n} i_{n, j}=s_{n} \\
i_{1,1}+i_{2,1}+\ldots+i_{n-1,1}+i_{n, 1}=\sum_{j=1}^{n} i_{j, 1}=d_{1} \\
i_{1,2}+i_{2,2}+\ldots+i_{n-1,2}+i_{n, 2}=\sum_{j=1}^{n} i_{j, 2}=d_{2} \\
\ldots \ldots \ldots \ldots \ldots \ldots \ldots \ldots \ldots \ldots \ldots \\
i_{1, n-1}+i_{2, n-1}+\ldots+i_{n-1, n-1}+i_{n, n-1}=\sum_{j=1}^{n} i_{j, n-1}=d_{n-1} \\
i_{1, n}+i_{2, n}+\ldots+i_{n-1, n}+i_{n, n}=\sum_{j=1}^{n} i_{j, n}=d_{n}
\end{array}\right.
$$

Thus, the problem acquires the meaning of determining the solutions of the linear equations systems with coefficients $(0,1)$. Obviously, there are $n^{2}$ unknown variables, and $2 n$ equations. One equation depends on others because it was imposed an additional equality condition of input and output information flows for all network nodes (3):

$$
s_{1}+s_{2}+\ldots+s_{n-2}+s_{n-1}+s_{n}=d_{1}+d_{2}+\ldots+d_{n-2}+d_{n-1}+d_{n}=S .
$$

The symbol $S$ means the sum of all flows in the network. Thus, the system (2) has $n^{2}$ unknown variables and only $2 n-1$ independent equations. So, among the solutions of the system there are only $n^{2}-(2 n-1)=(n-1)^{2}$ independent variables. The general solution of this system is convenient to find using the matrix form of the of linear algebraic equations system:

$$
\|A\| \cdot\|X\|=\|b\|
$$

The notation $\|A\|$ is used in (4) for $2 n \times n^{2}$ matrix consisting of the coefficients of the linear algebraic equations system (2). The notation $\|X\|$ is used for the unknown variables vector, with dimension $n^{2}$ and notation $\|b\|$ is for a vector of numbers $\left(s_{1}, s_{2}, \ldots, s_{n-1}, s_{n}, d_{1}, d_{2}, \ldots, d_{n-1}, d_{n}\right)$, with dimension $2 n$. More detaily matrix $\|A\|$ can be represented in the following form (5):

$$
\|A\|=\left(\begin{array}{cccc}
\left(1^{(n)}\right) & & & \left(0^{\left(n^{2}-n\right)}\right) \\
\left(0^{(n)}\right) & \left(1^{(n)}\right) & & \left(0^{\left(n^{2}-2 n\right)}\right) \\
\left(0^{(n)}\right) & \left(0^{(n)}\right) & \left(1^{(n)}\right) & \left(0^{\left(n^{2}-3 n\right)}\right) \\
\ldots & \ldots & \ldots & \ldots \\
\left(0^{\left(n^{2}-3 n\right)}\right) & \left(1^{(n)}\right) & \left(0^{(n)}\right) & \left(0^{(n)}\right) \\
\left(0^{\left(n^{2}-2 n\right)}\right) & & \left(1^{(n)}\right) & \left(0^{(n)}\right) \\
\left(0^{\left(n^{2}-n\right)}\right) & & & \left(1^{(n)}\right)
\end{array}\right), \quad\|X\|=\left(\begin{array}{c}
i_{1,1} \\
\cdots \\
i_{1, n} \\
i_{2,1} \\
\ldots \\
i_{2, n} \\
\ldots \\
i_{n, 1} \\
\ldots \\
i_{n, n}
\end{array}\right) .
$$

In (5) the notation $\left(1^{(n)}\right)$ is used for the sequence of $n$ ones, the notation $\left(0^{(n)}\right)$ is used for the sequence of $n$ zeros. 


\section{Main results}

\subsection{General Solution}

As mentioned above, there are $n^{2}$ unknown variables in the system (4), while it has only $2 n-1$ linearly independent equations. We should use Gaussian method for solving and firstly transform matrix $\|A\|$ to a simplified form (6):

$$
\|\tilde{A}\|=\left(\begin{array}{cc}
E_{2 n-1} & R \\
0 \ldots & 0
\end{array}\right)
$$

The simplified matrix $\|\tilde{A}\|$ is obtained by elementary transformations of rows of the matrix $\|A\|$ (permutations, addition and subtraction of rows), which do not change the solution of the initial system and permutations of columns of the matrix, which only change the order of unknown variables in the initial system. The simplified matrix has a block structure that contains a unit $(2 n-1)(2 n-1)$ matrix, and the matrix last row has only zero values. The matrix $\|R\|$ is $(2 n-1)\left(n^{2}-n+1\right)$ dimension with only values $(-1,0,1)$, as shown below in the example of the problem of $4 \times 4$ dimension.

Therefore one can express the general solution of the system in the following form (7):

$$
\|X\|=\left(\begin{array}{c}
\tilde{b} \\
\tilde{O}
\end{array}\right)+\left(\begin{array}{c}
-R \\
E_{n^{2}-n+1}
\end{array}\right) \cdot\|\Lambda\| .
$$

In (7) the notation $\tilde{b}$ means a column of numbers obtained by transformations of a free column $\|b\|$ of the system (4), $\tilde{O}$ is a column of zero values, $\|R\|$ is a matrix mentioned above, $\|\Lambda\|$ is a vector of $n-1$ dimension with positive integers components:

$$
\|\Lambda\|^{T}=\left(\lambda_{1}, \lambda_{2}, \ldots, \lambda_{n-2}, \lambda_{n-1}\right) .
$$

\subsection{Solution of $4 \times 4$ Dimension Problem}

Let us consider an example of the transport network of $4 \times 4$ dimension. The matrix of information flows is the next:

$$
I_{4,4}=\left(\begin{array}{cccc}
i_{1,1} & i_{1,2} & \ldots & i_{1, n} \\
i_{2,1} & i_{2,2} & \ldots & i_{2, n} \\
\ldots & \ldots & \ldots & \ldots \\
i_{n, 1} & i_{n, 2} & \ldots & i_{n, n}
\end{array}\right)
$$

The matrix of an equivalent system of the linear algebraic equations with an added column of flow values in each node is:

$$
\|A \mid b\|=\left(\begin{array}{ccccc}
1111 & 0000 & 0000 & 0000 & s_{1} \\
0000 & 1111 & 0000 & 0000 & s_{2} \\
0000 & 0000 & 1111 & 0000 & s_{3} \\
0000 & 0000 & 0000 & 1111 & s_{4} \\
1000 & 1000 & 1000 & 1000 & d_{1} \\
0100 & 0100 & 0100 & 0100 & d_{2} \\
0010 & 0010 & 0010 & 0010 & d_{3} \\
0001 & 0001 & 0001 & 0001 & d_{4}
\end{array}\right)
$$

Firstly the second, third and fourth rows are added to the first row, then subtracted the other four rows of the matrix, then change the order of the rows in the matrix, as shown in (11), it does not change the set of the system solutions: 


$$
\|A \mid b\| \rightarrow\left(\begin{array}{ccccc}
1000 & 1000 & 1000 & 1000 & d_{1} \\
0100 & 0100 & 0100 & 0100 & d_{2} \\
0010 & 0010 & 0010 & 0010 & d_{3} \\
0001 & 0001 & 0001 & 0001 & d_{4} \\
0000 & 1111 & 0000 & 0000 & s_{2} \\
0000 & 0000 & 1111 & 0000 & s_{3} \\
0000 & 0000 & 0000 & 1111 & s_{4} \\
0000 & 0000 & 0000 & 0000 & s_{1}+s_{2}+s_{3}+s_{4}-d_{1}-d_{2}-d_{3}-d_{4}=0
\end{array}\right)
$$

There are only zeros in the last row and matrix has a block in the form of a unit $4 \times 4$ matrix. Next, subtract the fifth line from the first line of the new matrix, and thus form a block in the form of a single matrix $5 \times 5$ :

$$
\|A \mid b\| \rightarrow\left(\begin{array}{ccccccc}
10000 & -1 & -1 & -1 & 1000 & 1000 & d_{1}-s_{2} \\
01000 & 1 & 0 & 0 & 0100 & 0100 & d_{2} \\
00100 & 0 & 1 & 0 & 0010 & 0010 & d_{3} \\
00010 & 0 & 0 & 1 & 0001 & 0001 & d_{4} \\
00001 & 1 & 1 & 1 & 0000 & 0000 & s_{2} \\
00000 & 0 & 0 & 0 & 1111 & 0000 & s_{3} \\
00000 & 0 & 0 & 0 & 0000 & 1111 & s_{4} \\
00000 & 0 & 0 & 0 & 0000 & 0000 & 0
\end{array}\right)
$$

In order to continue the formation of a unit matrix up to dimension $2 n-1=7$, you need to swap the sixth and ninth columns of the system and subtract from the first row the sixth one. Next you need to swap the seventh and thirteenth columns, and subtract the seventh row from the first row. The result is a simplified matrix $\|\tilde{A}\|$ :

$$
\|\tilde{A} \mid \tilde{b}\| \rightarrow\left(\begin{array}{ccccccccccc}
1000000 & -1 & -1 & -1 & -1 & -1 & -1 & -1 & -1 & -1 & d_{1}-s_{2}-s_{3}-s_{4} \\
0100000 & 0 & 1 & 1 & 0 & 0 & 0 & 1 & 0 & 0 & d_{2} \\
0010000 & 0 & 0 & 0 & 1 & 0 & 1 & 0 & 1 & 0 & d_{3} \\
0001000 & 1 & 0 & 0 & 0 & 1 & 0 & 0 & 0 & 1 & d_{4} \\
0000100 & 1 & 1 & 0 & 0 & 0 & 1 & 0 & 0 & 0 & s_{2} \\
0000010 & 0 & 0 & 1 & 1 & 1 & 0 & 0 & 0 & 0 & s_{3} \\
0000001 & 0 & 0 & 0 & 0 & 0 & 0 & 1 & 1 & 1 & s_{4} \\
0000000 & 0 & 0 & 0 & 0 & 0 & 0 & 0 & 0 & 0 & 0
\end{array}\right)
$$

Permutation of columns changes the order of system variables: $x_{6} \leftrightarrow x_{9}$ and $x_{7} \leftrightarrow x_{13}$, this must be taken into account when constructing matrices of information flows, the final result of the algorithm. Now we can write the elements of equation (7):

$$
\left(\begin{array}{c}
d_{1}-s_{2}-s_{3}-s_{4} \\
d_{2} \\
d_{3} \\
d_{4} \\
s_{2} \\
s_{3} \\
s_{4} \\
0 \\
0 \\
0 \\
0 \\
0 \\
0 \\
0 \\
0 \\
0
\end{array}\right) ; \quad\left(\begin{array}{c}
-R \\
E_{9 \times 9}
\end{array}\right)=\left(\begin{array}{ccccccccc}
1 & 1 & 1 & 1 & 1 & 1 & 1 & 1 & 1 \\
0 & -1 & -1 & 0 & 0 & 0 & -1 & 0 & 0 \\
0 & 0 & 0 & -1 & 0 & -1 & 0 & -1 & 0 \\
-1 & 0 & 0 & 0 & -1 & 0 & 0 & 0 & -1 \\
-1 & -1 & 0 & 0 & 0 & -1 & 0 & 0 & 0 \\
0 & 0 & -1 & -1 & -1 & 0 & 0 & 0 & 0 \\
0 & 0 & 0 & 0 & 0 & 0 & -1 & -1 & -1 \\
1 & 0 & 0 & 0 & 0 & 0 & 0 & 0 & 0 \\
0 & 1 & 0 & 0 & 0 & 0 & 0 & 0 & 0 \\
0 & 0 & 1 & 0 & 0 & 0 & 0 & 0 & 0 \\
0 & 0 & 0 & 1 & 0 & 0 & 0 & 0 & 0 \\
0 & 0 & 0 & 0 & 1 & 0 & 0 & 0 & 0 \\
0 & 0 & 0 & 0 & 0 & 1 & 0 & 0 & 0 \\
0 & 0 & 0 & 0 & 0 & 0 & 1 & 0 & 0 \\
0 & 0 & 0 & 0 & 0 & 0 & 0 & 1 & 0 \\
0 & 0 & 0 & 0 & 0 & 0 & 0 & 0 & 1
\end{array}\right) .
$$

Mathematical Modeling and Computing, Vol. 8, No. 4, pp. 821-829 (2021) 
Thus the column of independent variables has 9 elements:

$$
\|\Lambda\|=\left(\lambda_{1}, \lambda_{2}, \lambda_{3}, \lambda_{4}, \lambda_{5}, \lambda_{6}, \lambda_{7}, \lambda_{8}, \lambda_{9}\right)^{T} .
$$

For further analysis, we express the general solution as a system of equations (14), taking into account the reordering of variables mentioned above:

$$
\left\{\begin{array}{l}
x_{1}=d_{1}-s_{2}-s_{3}-s_{4}+\lambda_{1}+\lambda_{2}+\lambda_{3}+\lambda_{4}+\lambda_{5}+\lambda_{6}+\lambda_{7}+\lambda_{8}+\lambda_{9} \\
x_{2}=d_{2}-\left(\lambda_{2}+\lambda_{3}+\lambda_{7}\right) \\
x_{3}=d_{3}-\left(\lambda_{4}+\lambda_{6}+\lambda_{8}\right) \\
x_{4}=d_{4}-\left(\lambda_{1}+\lambda_{5}+\lambda_{9}\right) \\
x_{5}=s_{2}-\left(\lambda_{1}+\lambda_{2}+\lambda_{6}\right) \\
x_{6}=\lambda_{2} \\
x_{7}=\lambda_{6} \\
x_{8}=\lambda_{1} \\
x_{9}=s_{3}-\left(\lambda_{3}+\lambda_{4}+\lambda_{5}\right) \\
x_{10}=\lambda_{3} \\
x_{11}=\lambda_{4} \\
x_{12}=\lambda_{5} \\
x_{13}=s_{4}-\left(\lambda_{7}+\lambda_{8}+\lambda_{9}\right) \\
x_{14}=\lambda_{7} \\
x_{15}=\lambda_{8} \\
x_{16}=\lambda_{9}
\end{array}\right.
$$

Based on the content and statement of the problem, we look for the values of in-formation flows, which are non-negative integers. Therefore, the values of the column of independent system variables have limitations that can be written via the system (15) in the form of a system of inequalities:

$$
\left\{\begin{array}{l}
\lambda_{1}+\lambda_{2}+\lambda_{3}+\lambda_{4}+\lambda_{5}+\lambda_{6}+\lambda_{7}+\lambda_{8}+\lambda_{9} \geqslant s_{2}+s_{3}+s_{4}-d_{1}, \\
\lambda_{2}+\lambda_{3}+\lambda_{7} \leqslant d_{2} \\
\lambda_{4}+\lambda_{6}+\lambda_{8} \leqslant d_{3} \\
\lambda_{1}+\lambda_{5}+\lambda_{9} \leqslant d_{4} \\
\lambda_{1}+\lambda_{2}+\lambda_{6} \leqslant s_{2} \\
\lambda_{3}+\lambda_{4}+\lambda_{5} \leqslant s_{3} \\
\lambda_{7}+\lambda_{8}+\lambda_{9} \leqslant s_{4} \\
\lambda_{1}, \lambda_{2}, \lambda_{3}, \lambda_{4}, \lambda_{5}, \lambda_{6}, \lambda_{7}, \lambda_{8}, \lambda_{9} \geqslant 0 .
\end{array}\right.
$$

As can be seen from the system of inequalities (16), the problem of determining flows in a telecommunications network formed of $n$ nodes is reduced to a set of problems of dimension $n-1$ with an additional condition imposed on the sum of all flows in the system. Equality of total input and output flows in a problem with reduced dimension also applies, otherwise the set of solutions will be empty. Therefore, after recursion, the formal record of the problem looks like (17):

$$
\left\{\begin{array}{l}
\lambda_{1}+\lambda_{2}+\lambda_{6}=i_{s_{2}}, \text { where } i_{s_{2}} \in\left[0, s_{2}\right] \\
\lambda_{3}+\lambda_{4}+\lambda_{5}=i_{s_{3}}, \text { where } i_{s_{3}} \in\left[0, s_{3}\right] \\
\lambda_{7}+\lambda_{8}+\lambda_{9}=i_{s_{4}}, \text { where } i_{s_{4}} \in\left[0, s_{4}\right] \\
\lambda_{2}+\lambda_{3}+\lambda_{7}=i_{d_{2}}, \text { where } i_{d_{2}} \in\left[0, d_{2}\right] \\
\lambda_{4}+\lambda_{6}+\lambda_{8}=i_{d_{3}}, \text { where } i_{d_{3}} \in\left[0, d_{3}\right] \\
\lambda_{1}+\lambda_{5}+\lambda_{9}=i_{d_{4}}, \text { where } i_{d_{4}} \in\left[0, d_{4}\right] \\
i_{s_{2}}+i_{s_{3}}+i_{s_{4}}=i_{d_{2}}+i_{d_{3}}+i_{d_{4}} \\
\sum_{i=1}^{9} \lambda_{i} \geqslant s_{2}+s_{3}+s_{4}-d_{1}
\end{array}\right.
$$

\subsection{Algorithm development and software implementation}

Thus, the found regularities make it possible to determine the set of solutions of the problem by reducing it to a problem of smaller dimension, i.e. by applying the recursion method. The problem is reduced to solving a set of problems smaller by one dimension with the values of input and output flow in each node, which are given by integers from the intervals. The lower limits of these intervals 
are the smallest possible flows values, i.e. zero, and the largest value coincides with one of the values of the initial problem, as can be seen from (16).

Software implementation of the algorithm is to develop modules that define the set of solutions of the problem for some fixed dimension. Each such module has a recursive call to another module, with reduced by one dimension, which occurs in the loop for the flow limit values specified by integers from the range of values. Thus, the 2-dimension problem is the basic problem for matrices of other dimensions. Therefore, we write the equation for its solution.

The initial system of equations of the basic problem of dimension $2 \times 2$ is:

$$
\left\{\begin{array}{l}
x_{1}+x_{2}=s_{1}, \\
x_{3}+x_{4}=s_{2}, \\
x_{1}+x_{3}=d_{1} \\
x_{2}+x_{4}=d_{2} .
\end{array}\right.
$$

The general solution of the system (17) is as (18):

$$
\|X\|=\left(\begin{array}{c}
d_{1}-s_{2} \\
d_{2} \\
s_{2} \\
0
\end{array}\right)+\lambda\left(\begin{array}{c}
1 \\
-1 \\
-1 \\
1
\end{array}\right) .
$$

This solution must be nonnegative and therefore a system of inequalities holds:

$$
\left\{\begin{array}{l}
d_{1}-s_{2}+\lambda \geqslant 0 \\
d_{2}-\lambda \geqslant 0 \\
s_{2}-\lambda \geqslant 0 \\
\lambda \geqslant 0
\end{array}\right.
$$

Therefore, we can determine the set of values of the number $\lambda$, which is an interval with minimum and maximum values defined as follows:

$$
\left\{\begin{array}{l}
\lambda \in\left[L_{\min }, L_{\max }\right], \\
L_{\min }=\max \left(0, s_{2}-d_{1}\right), \\
L_{\max }=\min \left(d_{2}, s_{2}\right) .
\end{array}\right.
$$

The algorithm is tested in the Skylab environment. The following is the code of the program for the problem of dimension 3, in which the recursive call of the program for the problem of dimension 2 is used (which is denoted as $s l v 2(s c, d c)$ ).

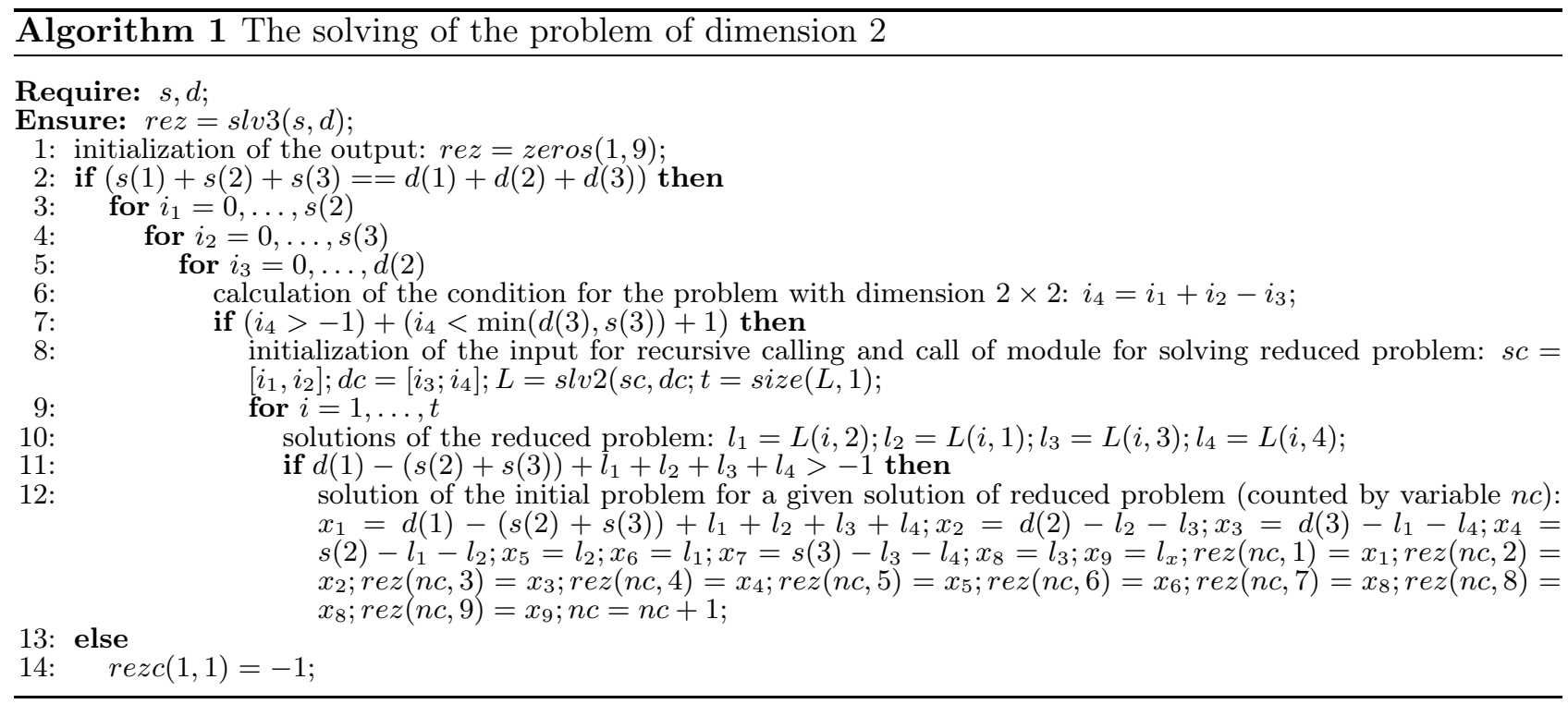




\section{Extrapolation of results on a network with large dimensions and conclusions}

The developed algorithm is used to determine the total number of solutions depending on the total value of information flows for network with dimension $n$ :

$$
S=\sum_{i=1}^{n} s_{i}=\sum_{i=1}^{n} d_{i} .
$$

For two nodes the problem is not very complicated and we determine the total number of solutions for the total flow in 0.5 hour. For two nodes, this is almost a second-order polynomial function. An analytical approximation of dependence of the total number of integer solutions $N$ on the overall flow in network is as follows:

$$
N_{2}(S)=10915 S^{2}+161010 S+413385 .
$$

Due to the huge computational complexity of this problem, the value of $S$ is limited for other two node numbers. So, calculation time is restricted by two hours, and for three nodes date are obtained for the total flow up to 20 , for four nodes the total flow value is 10 .

Results of calculations are shown Table 1 and Table 2 for networks with 3 and 4 nodes respectively.

Table 1. Results of calculations for 3 nodes.

\begin{tabular}{|c|c|}
\hline The value of total traffic $S$ & The total number of solutions \\
\hline 0 & 1 \\
1 & 9 \\
2 & 43 \\
3 & 150 \\
4 & 432 \\
5 & 1088 \\
6 & 2478 \\
7 & 5213 \\
8 & 10280 \\
9 & 19207 \\
10 & 34279 \\
11 & 58811 \\
12 & 97491 \\
13 & 156800 \\
14 & 245524 \\
15 & 375366 \\
16 & 561675 \\
17 & 824301 \\
19 & 1188595 \\
20 & 1686564 \\
\hline
\end{tabular}

Table 2. Results of calculations for 4 nodes.

\begin{tabular}{|c|c|}
\hline The value of total traffic $S$ & The total number of solutions \\
\hline 0 & 1 \\
1 & 16 \\
2 & 126 \\
3 & 697 \\
4 & 3095 \\
5 & 11761 \\
6 & 39629 \\
7 & 121096 \\
8 & 340900 \\
9 & 894601 \\
10 & 2208787 \\
\hline
\end{tabular}

Mathematical Modeling and Computing, Vol. 8, No. 4, pp. 821-829 (2021) 
Data shown in Table 1 and Table 2 allow to obtain extrapolation expression for estimation the total number of solutions for bigger flows in network. Extrapolation formulas for total number of solutions are in the following form:

$$
\begin{gathered}
N_{3}(S)=9.8894 e^{0.6553 S}, \\
N_{4}(S)=1.3022 e^{0.394 S} .
\end{gathered}
$$

Based on results of recursive model one can conclude that there is almost exponential dependence on the overall flow in network both for three and four nodes.

\section{Conclusions}

Reducing the problem definition of a problem solution for a network with more than 2 nodes to smaller problems is a successful solution to the problem in terms of reducing the analytical complexity of the problem. Finally, you only need to find the whole set of solutions for a two-node network. However, the use of recursion leads to a significant increase in the time to solve a problem that uses recursion, even for a network consisting of only three nodes. Despite the small values of the flows, the obtained results enable to cluster the paths in the network according to the possible values of the flows, and the larger the limit value of the total flow, the finer this clustering is. The value of the number of nodes is also small, but still allows you to analyze the processes of traffic in the nodes closest to the specified node.

[1] Politanskyi R., Klymash M. Application of Artificial Intelligence in Cognitive Radio for Planning Distribution of Frequency Channels. 2019 3rd International Conference on Advanced Information and Communications Technologies (AICT). 390-394 (2019).

[2] Bobalo Y. Y., Horbatyi I. V., Kiselychnyk M. D., Medynsky I. P., Melen M. V. Semi-Markov reliability model of functioning of wireless telecommunication system with complex control system. Mathematical Modeling and Computing. 6 (2), 192-210 (2019).

[3] Veryga A., Politanskyi R., Lesinskyi V., Ruda T. Analysis of Using of Fractal Signals for Noise Immune Information Transmission Systems. 15th International Conference on Advanced Trends in Radioelectronics, Telecommunications and Computer Engineering (TCSET). 162-165 (2020).

[4] Kushnir M., Vovchuk D., Haliuk S., Ivaniuk P., Politanskyi R. Approaches to building a chaotic communication system. Lecture Notes on Data Engineering and Communications Technologies. 48, 207-227 2021.

[5] Galiuk S. D., Kushnir M. Y., Politanskyi R. L. Communication with use of symbolic dynamics of chaotic systems. 2011 21st International Crimean Conference: Microwave and Telecommunication Technology Proceedings. 423-424 (2011).

[6] Politanskyi R., Veryga A., Vistak M. Analysis of facing developers problems of modern telecommunication technologies. CEUR Workshop Proceedings. 109-117 (2020).

[7] Strykhalyuk B., Kaidan M., Klymash M., Kryvinska N. Tensor models for the efficient multipath routing in large-scale communication networks. Proceedings of the 12th International Conference on Information Integration and Web-based Applications and Services. 818-821 (2010). 


\title{
Дослідження інформаційних потоків у мережі
}

\author{
Політанський Р. Л. ${ }^{1}$, Зарицька О. Л. ${ }^{2}$, Вістак М. В. ${ }^{3}$, Власенко В. В. ${ }^{1}$ \\ ${ }^{1}$ Чернівецький національний університет імені Юрія Федъковича, \\ вул. Кочюбинсъкого 2, 58012, Четнівиі, Україна \\ ${ }^{2}$ Національний університет Лъвівсъка політехніка, \\ вул. Бандери 12, 79013, Львів, Україна \\ 3 Львівсъкий начіональний медичний університет імені Данила Галищъкого, \\ вул. Пекарсъка 69, 79010, Львів, Україна
}

Розроблено та досліджено алгоритм визначення інформаційних потоків у мережі за обмежень на значення вхідних та вихідних потоків у кожному вузлі системи. Алгоритм грунтується на гауссівському методі розв'язування систем лінійних рівнянь 3 рангом еквівалентної матриці системи, що нижче за кількість невідомих змінних у системі. На основі цього алгоритму розраховуються ємності наборів цілочисельних рішень для мереж з 2 вузлами (інтенсивність потоку до 200), 3 вузлами (інтенсивність потоку до 20) та 4 вузлами (інтенсивність потоку до 10).

Ключові слова: метод Гаусса, множина розв'язків системи лінійних рівнянь, транспортна мережа. 